\title{
СОЗЕРЦАНИЕ КАК ЛИТИЧЕСКАЯ ФОРМА РЕГУЛЯЦИИ СМЫСЛОВОЙ СФЕРЫ ЧЕЛОВЕКА
}

\section{Акопов Гарник Владимирович}

Исследование выполнено при финансовой поддержке РГНФ в рамках проекта проведения научных исследований ("Созерцание в категориальной системе современной психологии: теоретические и прикладные аспекты»), проект № 12-06-00595.

Созериание рассматривается в статье как неотъемлемая часть психической жизни и форма регуляции смысловой сферы человека: как спонтанносмысловой контроль при разрешении внутриличностных конфликтов, некая функция обретения или расставания, трансформации или коррекции отдельных смыслов или смысловой сферы личности в челом.

Показывается нетождественность созерцания перцептивным, аттенционным, мнемическим и иным когнитивным, аффективным и интенциональным состояниям. Созерцание является особым состоянием сознания и соотносится с релевантным психическим явлением, потенциально выступающим в формах прочесса, состояния и свойства субъекта.

Ключевые слова: созериание, созериательность, смысл, смысловая сфера, эквипотенциальность созерцания.

\section{CONTEMPLATION AS A LYTIC FORM OF THE PERSON'S SENSE SPHERE REGULATION}

\section{Akopov Garnik Vladimirovich}

The research is carried out with financial support of the Russian Humanitarian Scientific Foundation (RHSF) within the limits of the project of carrying out scientific researches ("Contemplation in the categorial system of modern psychology: theoretical and applied aspects"), project no. 12-06-00595.

The article considers contemplation as an integral part of mental life and a form of the person's sense sphere regulation, as a spontaneous-sense control in resolving 


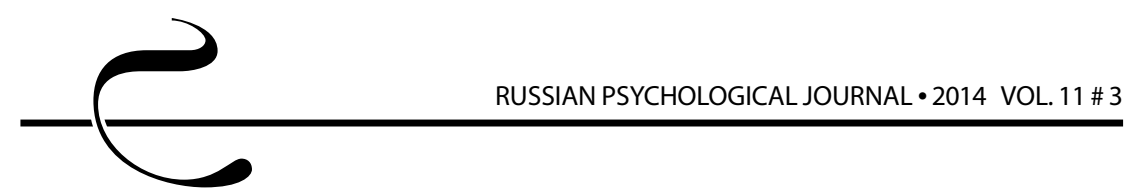

intrapersonal conflicts, a certain function of finding or parting, transformation or correction of certain senses or the person's sense sphere as a whole.

The author shows that contemplation can't be reduced to perceptual, attentional, mnemonic and other cognitive, affective and intensional states. Contemplation is a special state of consciousness, and it correlates with a relevant mental phenomenon which is potentially displayed in forms of the subject's feature, state, and process.

Keywords: contemplation, contemplativeness, sense, sense sphere, equipotentiality of contemplation.

Ставшее широко популярным в последние годы понятие «смысл» во многом несет в себе содержание понятий «отношение» и «установка». Весьма масштабный и обстоятельный психологический анализ понятий, видов, структурных, динамических и т. д. построений, связанных со смысловой сферой человека, осуществлен Д. А. Леонтьевым [22].

Новое теоретико-прикладное изучение психологической проблематики смысла осуществлено в работе Л. М. Дубового [16].

В другой яркой работе, выстраивающей макет перспективной «смысловой теории сознания», напротив, остается недостаточно раскрытой сама тема смысла, его сущностная и содержательная характеристика. «Ведь не память же это, на самом деле?» - спрашивает В. М. Аллахвердов [2]. В этом плане любопытно суждение В. В. Знакова, отмечающего, что «как только психологи обращают внимание на смысл, они вольно или невольно переходят в плоскость исследования понимания. Понимание - это всегда смыслообразование, потому что неосмысленные знания о мире для субъекта мертвы» [18].

Предпринятый С. И. Голенковым детальный этимологический и системносемантический анализ слова «смысл» позволил автору определить наиболее полное содержание соответствующего значения. Как отмечает С. И. Голенков, приставка «с» в слове «смысл» («со-мысль») «подчеркивает аспект связанности, упорядоченности, организованности мыслительного содержания. Смысловое соединение мыслей есть не просто суммативное механическое образование, но целостность, новое, отличное от прежнего единство мыслей» [13, с. 22]. К сожалению, автор весьма оригинальной философской концепции «культура - смысл - сознание» не счел важным выделить в значении слова “смысл» коммуникативный (интер-интро) аспект, т. е. межличностное или внутриличностное «созвучие» (консонанс, полифония) мыслей [там же].

Главный парадокс смысловой конструкции сознания или смысла как «первого и главного измерения человеческого сознания и бытия» $[17$, с. 318] состоит в том, что «полный перевод с языка значений на язык смыслов 
и с языка смыслов на язык значений невозможен» [там же, с. 276]. Такую Взаимную «нетранслируемость» значения и смысла В. П. Зинченко объясняет «свободой мысли» и, ссылаясь на М. М. Бахтина, «бездонностью всякого смысла». Видимо, неслучайно В. П. Зинченко в вышеприведенном утверждении объединил сознание и бытие.

Суть парадокса, на наш взгляд, в том, что «смысловые установки могут быть как осознаваемы, так и неосознаваемы» [7, с. 89]. А. Г. Асмолов отмечает, что «в отличие от сферы знаний и умений смысловые образования личности не поддаются непосредственному произвольному контролю. Включенность смысловых образований в породившую их деятельность и неподвластность этих образований непосредственному произвольному контролю составляют их важнейшую особенность» [там же, с. 294]. Более того, смысловые образования независимы от сознания в смысле их «некодифицируемости», т. е. «невозможности прямого воплощения в системе значений» [там же, с. 295]. Мысль А. Г. Асмолова становится вполне понятной в контексте развиваемой им обобщенной теории установки и концепции многомерных миров личности и, соответственно, нетождественности, в частности, языков вербальной и невербальной коммуникации. В последнем случае, как считает А. Г. Асмолов, в большей мере проявляются смысловые установки личности. Другое важное утверждение А. Г. Асмолова, определяющее неоднозначность соотношения сознания и смысла, заключается в том, что «личностный смысл может быть осознан субъектом, но самого по себе осознания недостаточно для изменения личностного смысла» [7, с. 410]. Изменения (зарождение, коррекция, трансформация и т. д.), на наш взгляд, связаны с явлением созерцания.

Созерцание как философское понятие можно соотнести с релевантным психическим явлением, потенциально выступающим в формах процесса, состояния и свойства субъекта (индивида, личности, индивидуальности) [5]. Характеризуемое как отражение, оно может как приобретать, так и терять активность (свободу, интенциональность, направленность, опосредованность и т. д. и т. п.) будучи равноправным выражением «реальности субъекта» и «реальности объекта» [34]. Инверсируя от внешнего к внутреннему и наоборот, созерцание может охватывать своим «вниманием» самые разнообразные предметы, объекты, явления, сущности, процессы, состояния и т. д., создавая и разрушая типологии, классификации, соединения, разъединения, целое и составные части, композиции и деконструкции. В биоэволюционном и нервно-психическом планах созерцание можно соотнести с состоянием сосредоточения [9]. Следует отметить, что источником, средством или «орудием» созерцания выступает не только визуальная система: определенное соотношение звуков (шум ветра, звуки леса, птичий гомон, протяжная песня, симфоническая или иная композиция и др.), внутрителесных 
и поверхностно-мышечных гармоничных ощущений (легкое насыщение, посильное физическое напряжение, первичное утомление и т. д.), спокойное длительное движение, полет и др. Созерцание в синхронии можно обозначить как состояние необремененности прошлым и неозабоченности будущим в благообретенном настоящем.

Достаточно сложен и характер отношений созерцания с базовыми психическими процессами и состояниями. Оно конгруэнтно вниманию, не совпадая с ним (ненаправленное сосредоточение, задумчивость). Созерцание может быть обращено из настоящего в прошлое или наоборот, дезориентируя работу памяти. Оно может быть восприятием явного (реального) и ирреального, контаминируя перцепцию с воображением. «Окунаясь» в будущее, оно не равносильно грезам и мечтаниям. Чуждое опосредованию, оно (созерцание) не мыслит и, вместе с тем, постигает сущность. Не откликаясь ни на одну из поименованных в науке эмоций, созерцание, возможно, несет в себе магию Леонардовской Джоконды, и вместе с ней полное отсутствие мотивации и видимого осознаваемого действия.

Уравнивая реальности субъекта и объекта, созерцание выступает оппозицией (антиномией) деятельности, подтверждая, а в отдельных случаях разрушая единство деятельности и сознания [34]. Созерцание противостоит также прагматизму (утилитаризму, корысти, ангажированности и т. д.) не только в одной из своих разновидностей - эстетическом созерцании (И. Кант). В своей «неподвижной» противоположности любому вектору движения, действия («подвес», «зазор») [23] созерцание подобно светоносному (озаряющему) состоянию. Вместе с тем оно не тождественно состояниям озарения (медитации) или инсайта, т. к. то и другое выступают итоговыми фазами целенаправленного поиска, ожидаемого решения заранее поставленной задачи. Созерцание свободно, т. к. неподвластно регуляции. Свобода или случайность (спонтанность) выражаются в том, что это состояние может актуализироваться, а возможно и нет, так же, как и его смысловое оформление. Это проявляется также в том, что, как отмечают К. А. Абульханова-Славская и А. Н. Славская в комментариях к работе С. Л. Рубинштейна «Человек и мир», «созерцание выражает способность субъекта "верно отнестись к миру", т. е. определить характер и "логику" своего к нему отношения» [1, с. 422].

«Свободная» динамика созерцания связана с выявленной А. В. Брушлинским «непрерывностью осознанного и неосознанного, представляющей собой одно из фундаментальных свойств психического как процесса» [11]. В этом смысле важно также положение А. В. Брушлинского о том, что «непрерывность (континуальность) психического всегда существует одновременно на разных, но взаимосвязанных уровнях осознанного и неосознанного» [там же]. 
В эту логику хорошо вписывается «постановка проблемы психических состояний в контексте системы «человек - окружающая среда». В. И. Панов определяет «процессуальное анизотропное отношение» как «отношение между последующим и предшествующим дискретными актами (микро- и макро-) психического процесса. Причем предшествующий акт выполняет по отношению к последующему своеобразную антиципирующую роль. Вследствие чего последующий акт происходит не "сам по себе", а через опосредствование ("на фоне", "в контексте") предшествующего акта» [28, с. 111]. Этот эффект «становящихся форм» хорошо иллюстрируется в описании В. Ф. Петренко и В. В. Кучеренко: «концентрируясь "здесь и сейчас" на вид величественной горной гряды или глядя на горизонт великого океана, мы испытываем состояния, близкие к тем, что испытывал другой человек, стоявший на этом месте и погруженный в созерцание столетия назад. В этот момент времени прошлое и настоящее, а также будущее (в восприятии еще не родившегося человека) сливаются, и мы чувствуем бездну вечности» [31].

В феноменологическом плане «подлинность» созерцания как специфического состояния в многообразии психических явлений нуждается в разнообразных подтверждениях. Диахрония языка, порождая неологизмы и новые устойчивые словосочетания, обращает другие, ранее распространенные слова, в архаизмы или в языковую экзотику, что можно отнести и к слову «созерцание». Вместе с тем, согласно А. В. Брушлинскому, «осознанное не сводится к вербализованному», т. е. нет полного соответствия, тем более тождества между неосознанным и невербализованным (нетождественность осознанного и вербализованного) [11]. Таким образом, даже отсутствие в повседневной речи, в языке словесного обозначения определенного (в ином обосновании) психического состояния не свидетельствует о невозможности или отсутствии этого состояния в субъективной реальности.

Другое возможное возражение к «институализации» состояния созерцания - образ жизни современного человека. Эффекты современной глобализации [3], казалось бы, не оставляют «места» для созерцания. Вместе с тем достаточно резонансно звучит призыв «создать новый стиль жизни, включить паузу созерцания (подчеркнуто нами. - Г. А.) в череду дел, избавиться от лихорадки деятельности..., обратить стремления к "цивилизации созерцания"» [32]. Помимо ценностного отношения существует также серьезная когнитивная аргументация, подтверждающая реальность феномена созерцания. Так, многообразие существующих сущностных трактовок термина «созерцание»: перцептивная, аттенционная, интеллектуальная (включая инсайт, интуицию и др.), эмоциональная, эстетическая и т. д. (см. Г. В. Акопов, И. Е. Гарбер, Э. Г. Григорян, И. Н. Карицкий и др.) $[5,12,14,20]$ демонстрирует теоретическую насыщенность и объемный потенциал «дремавшего» все 
последнее время как в рамках философских, так и научно-психологических изысканий, понятия.

Онтология рассматриваемого явления в ретроспекции созерцания, а также в субъективных представлениях разновозрастной, в том числе молодежной выборки оказалась столь же богатой и разномодальной (Л. С. Акопян, Н. А. Низовских, Т. В. Семёнова, и др.) [6, 27, 36]. Основными признаками созерцания являются: внезапность, непреднамеренность вхождения, отвлечение от всего предшествовавшего, остановка движений, более или менее затрудненное реагирование на внешние стимулы, спокойный выход из состояния, отсутствие содержательной информации об испытанном состоянии, отсутствие каких-либо специфических эмоций в данном состоянии. Богатая онтология созерцания представлена в религиозных «практиках», в особенности в Православии (молитва, монашество, затворничество и др.) [37]. Эти практики представляют исторически первоначальный сознательный функциональный план «институционализации» созерцания.

В повседневной жизни несомненна адаптивная (или «сверхадаптивная», по В. А. Петровскому) функция созерцания, начиная с незаметных (неосознаваемых) микропауз - до макросостояний, инициированных, как правило, восприятием отдаленных и природных объектов [30]. Помимо регуляционной, можно верифицировать также энергетическую (состояние, аналогичное легкому утомлению, расслаблению или, наоборот, энергетической «накачке» и др.), интеграционную функции, а в личностном плане - функцию развития. И. А. Красильников рассматривает созерцание как спонтанно-смысловой контроль субъекта при разрешении внутриличностных конфликтов [21], т. е. как функцию обретения или расставания, трансформации или коррекции отдельных смыслов или смысловой сферы личности в целом. Соответствующий временной интервал М. К. Мамардашвили обозначает как «точку интенсивности» («избыточная интенсивность»), изменяющую смыслы нашей жизни [23, с. 32-33]. Как созерцательную основу художественного творчества рассматривает А. А. Мелик-Пашаев «созерцательное отношение» в эквивалентности с эстетическим отношением к жизни [24].

В возрастно-психологическом плане созерцание приобретает доминантную роль (А. Ухтомский) в периоды возрастных и иных кризисов, наиболее явно обнаруживаясь в младенчестве, в юности и в преклонном возрасте. Здесь уместно привести феноменологическое описание порождаемых в созерцании состояний «возрастания интеграции личности», «обновления ощущения личной ценности и собственных потенциальных творческих возможностей после выхода из состояния», отмечаемых А. О. Прохоровым и В. Д. Бехтеревой [33, с. 280]. Возможны и иные последствия созерцания, как то: пересмотр отношения к миру и себе, трансформация смысловых образований и др. Таким 
образом, становление и развитие смысловой сферы как системы отношений человека может осуществляться в литической и критической формах.

Некоторые заболевания «благоприятствуют» актуализации созерцания (см. повесть Л. Н. Толстого «Смерть Ивана Ильича»), посредством которого проявляются скрытые контексты и обнажаются иные смыслы. В этом плане важно отчетливо дифференцировать явления созерцания и переживания. В последнем случае неотъемлемой и существенной характеристикой является эмоциональная составляющая. Для созерцания эмоциональная сторона вовсе не обязательна. Согласно И. Сирину (VII в.) «бесстрастие является непременным условием дарования созерцания» [37]. Это не противоречит мнению, что «психические состояния "метятся" знаком и модальностью эмоциональных переживаний» [19]. Хотя состояние созерцания не несет каких-либо внешних проявлений эмоциональности (человек, пребывающий в состоянии созерцания, узнаваем по его отрешенности от окружающего мира), предшествовавший созерцанию знак и модус эмоции сохраняется на протяжении всего периода созерцательной «остановки», трансцендируя в состояние постсозерцательной удовлетворенности. По аналогии со специфическим физическим явлением соотношение состояния созерцания с эмоциональными состояниями можно обозначить как эмоциональную эквипотенциальность созерцания.

В целом при всем многообразии понимания и трактовки понятия «созерцания», можно констатировать: позитивное отношение коммуникантов к термину; интерес к его значению и ретроспективному «оживлению», смысловым наполнениям со стороны всех привлекаемых к исследованию участников; фиксируется значительно более частое синтагматическое соединение созерцания со словом «состояние», в сравнении с «процессом» и «свойством» личности; показана нетождественность и несводимость состояния созерцания к перцептивным, аттенционным, мнемическим и иным когнитивным, аффективным и интенциональным состояниям; созерцание носит спонтанный (непреднамеренный), неэмоциональный, нерегулируемый характер, уравнивая «потенциалы» органического, психического и социального порядка; в «паузах созерцания» неосознанно трансформируются, корректируются, зарождаются, либо сходят на «нет» смысловые структуры разного уровня. Если в деятельности как сознательной, целенаправленной активности реализуются предварительно сформированные смыслы, то в созерцании, как остановке деятельности, неосознанно вызревают (состояние), корректируются или трансформируются (процесс) и закрепляются (свойство личности) новые смысловые образования. В этом плане классический порядок (последовательность) «процессы - состояния - свойства», принятый по временному критерию (менее - более продолжительные 
явления), в случае созерцания, как правило, инверсируется в первой паре триады «состояние - процесс». В случаях достаточно выраженной представленности созерцательности как индивидуально-психологической особенности личности, данное свойство выступает стабилизирующим или «тормозящим» деятельность смысловым механизмом.

\section{Литература}

1. Абульханова-Славская К. А., Славская А. Н. Комментарии. Человек и мир // Рубинштейн С. Л. Бытие и сознание. Человек и мир. - СПб., 2003. С. 406-426.

2. Агафонов А. Ю. Основы смысловой теории сознания. - СПб.: Речь, 2003.

3. Акопов Г. В. Глобализация и самоопределение личности в современном обществе // Профессиональное и личностное самоопределение молодежи в современной России: материалы IV Всероссийской научно-практической конференции / Отв. ред. А. В. Капцов. - Самара: СамЛюксПринт, 2013 - С. 3-8.

4. Акопов Г. В. Методологические основания концепта «созерцание» в современной психологии // Созерцание как современная научнотеоретическая и прикладная проблема: материалы Всероссийской конференции / Под ред. Г. В. Акопова, Е. В. Бакшутовой. - Самара: Изд-во ПГСГА, 2013. - С. 10-17.

5. Акопов Г. В. Созерцание как предмет психологических исследований // Материалы Поволжского консолидирующего семинара «Созерцание как современная научно-теоретическая и прикладная проблема» / Отв. ред. Г. В. Акопов. - Самара: Изд-во ПГСГА, 2011. - С. 36-44.

6. Акопян Л. С. Представления о феномене созерцания у студентов // Созерцание как современная научно-теоретическая и прикладная проблема: материалы Всероссийской конференции / Под ред. Г. В. Акопова, Е. В. Бакшутовой. - Самара: Изд-во ПГСГА, 2013. - С. 144-147.

7. Асмолов А. Г. По ту сторону сознания: методологические проблемы неклассической психологии. - М.: Смысл, 2002.

8. Бакшутова Е. В. Об аксиологическом контексте созерцания // Созерцание как современная научно-теоретическая и прикладная проблема: материалы Всероссийской конференции / Под ред. Г. В. Акопова, Е. В. Бакшутовой. - Самара: Изд-во ПГСГА, 2013. - С. 74-82.

9. Бехтерев В. М. Объективная психология. - М.: Наука, 1991.

10. Бодров В. А. Современные представления о чувстве усталости в профессиональной деятельности // Психологический журнал. - 2012. T. 33. - № 2. - C. 23-34. 
11. Брушлинский А. В. Проблема бессознательного в трудах С. Л. Рубинштейна // Вопросы психологии. - 1979. - № 3. - С. 115-122.

12. Гарбер И. Е. Созерцание и сознание: сравнительный когнитивный анализ // Созерцание как современная научно-теоретическая и прикладная проблема: материалы Поволжского консолидирующего семинара / Отв. ред. Г. В. Акопов. - Самара: Изд-во ПГСГА, 2011. - С. 44-49.

13. Голенков С. И. Культура, смысл, сознание. - Самара: Самарский университет, 1996.

14. Григорян Э. Г. Созерцание или «внимательное наблюдение» // Созерцание как современная научно-теоретическая и прикладная проблема: материалы Поволжского консолидирующего семинара / Отв. ред. Г. В. Акопов. - Самара: Изд-во ПГСГА, 2011. - С. 49-55.

15. Дорошко К. Г. Соотношение понятий «оцепенение» и «созерцание» // Созерцание как современная научно-теоретическая и прикладная проблема: материалы Всероссийской конференции, Самара / Под ред. Г. В. Акопова, Е. В. Бакшутовой. - Самара: Изд-во ПГСГА, 2013. - С. 37-40.

16. Дубовый Л. М. Введение в психологию смысла. - Пенза, 2006.

17. Зинченко В. П. Психологические основы педагогики. - М.: Гардарики, 2002.

18. Знаков В. В. Самосознание, самопонимание и понимающее себя бытие // Методология и история психологии. - 2007. - Т. 2. - Вып. 3. - С. 65-74.

19. Ильин Е. П. Эмоции и чувства. - СПб.: Питер, 2001.

20. Карицкий И. Н. Психологические практики внутреннего созерцания реальности // Созерцание как современная научно-теоретическая и прикладная проблема: материалы Поволжского консолидирующего семинара / Отв. ред. Г. В. Акопов. - Самара: Изд-во ПГСГА, 2011. C. 112-127.

21. Красильников И. А. Созерцательность как спонтанно-смысловой контроль субъекта при разрешении внутриличностных конфликтов // Созерцание как современная научно-теоретическая и прикладная проблема: материалы Поволжского консолидирующего семинара / Отв. ред. Г. В. Акопов. - Самара: Изд-во ПГСГА, 2011 - С. 192-197.

22. Леонтьев Д. А. Психология смысла: природа, строение и динамика смысловой реальности. - М.: Смысл, 1999.

23. Мамардашвили М. К. Картезианские размышления. - М.: Прогресс; Культура, 1993.

24. Мелик-Пашаев А. А. О созерцательной основе художественного творчества // Созерцание как современная научно-теоретическая и прикладная проблема: материалы Поволжского консолидирующего семинара / Отв. ред. Г. В. Акопов. - Самара: Изд-во ПГСГА, 2011. - С. 202-208. 


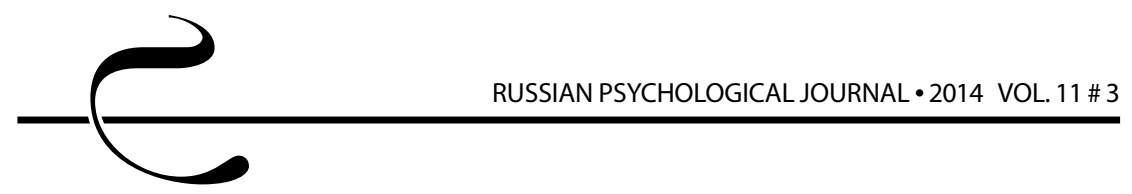

25. Молчанов В. И. Исследования по феноменологии сознания. - М.: Территория будущего, 2007.

26. Мухрыгина О.И. Созерцательный аспект саморегуляции состояний человека // Созерцание как современная научно-теоретическая и прикладная проблема: материалы Поволжского консолидирующего семинара / Отв. ред. Г. В. Акопов. - Самара: Изд-во ПГСГА, 2011. - С. 208-211.

27. Низовских Н. А., Николаев С. Г., Втюрина Т. А. Ментальные репрезентации созерцания // Созерцание как современная научно-теоретическая и прикладная проблема: материалы Всероссийской конференции / Под ред. Г. В. Акопова, Е. В. Бакшутовой. - Самара: Изд-во ПГСГА, 2013. - С. 147-155.

28. Панов В. И. Введение в экологическую психологию. - М.: Школьные технологии, 2006.

29. Пергаменщик Л. А. Психическое оцепенение как разрыв непрерывности бытия // Журнал практического психолога. - 2009. - № 1. - С. 156-165.

30. Петренко В. Ф. Духовно-психологическое и естественнонаучное обоснование созерцания // Созерцание как современная научнотеоретическая и прикладная проблема: материалы Всероссийской конференции / Под ред. Г. В. Акопова, Е. В. Бакшутовой. - Самара: Изд-во ПГСГА, 2013. - С. 6-10.

31. Петренко В. Ф., Кучеренко В. В. Медитация как неопосредованное познание // Методология и история психологии. - 2007. - Т. 2. - Вып. 1. C. 164-190.

32. Померани Г. С. Пауза созерцания // Дружба народов. - 2002. - № 2. URL: http://magazines.russ.ru/druzhba/2002/2/pom.html

33. Прохоров А. О., Бехтерева В. Д. Измененные состояния сознания // Психология состояний / Под ред. А. О. Прохорова. - М.: Когито-Центр, 2011. - С. 277-306.

34. Рубинштейн С. Л. Бытие и сознание / Человек и мир. - СПб., 2003.

35. Рулина Т. К. Западноевропейская традиция умного зрения // Созерцание как современная научно-теоретическая и прикладная проблема: материалы Всероссийской конференции / Под ред. Г. В. Акопова, Е. В. Бакшутовой. - Самара: Изд-во ПГСГА, 2013. - С. 66-74.

36. Семёнова Т. В. О проблемах диагностики созерцания // Созерцание как современная научно-теоретическая и прикладная проблема: материалы Всероссийской конференции / Под ред. Г. В. Акопова, Е. В. Бакшутовой. Самара: Изд-во ПГСГА, 2013. - С. 155-159.

37. Шестун Г., Подоровская И. А. Святоотеческое понимание созерцания // Созерцание как современная научно-теоретическая и прикладная проблема: материалы Поволжского консолидирующего семинара / Отв. ред. Г. В. Акопов. - Самара: Изд-во ПГСГА, 2011. 


\section{References}

1. Abul'khanova-Slavskaia K. A., Slavskaia A. N. Kommentarii. Chelovek i mir. Rubinshtein S. L. Bytie i soznanie. Chelovek i mir [Comments. A man and the world. Rubenstein S. L. Being and consciousness. A man and the world]. St. Petersburg, 2003, pp. 406-426.

2. Agafonov A. lu. Osnovy smyslovoi teorii soznaniia [Bases of the sense theory of consciousness]. St. Petersburg, Rech'Publ., 2003.

3. Akopov G. V. Globalizatsiia i samoopredelenie lichnosti v sovremennom obshchestve [Globalization and self-determination of personality in modern society]. Materialy IV Vserossiiskoi nauchno-prakticheskoi konferentsii "Professional'noe ilichnostnoe samoopredelenie molodezhiv sovremennoi Rossii" [Proc. the IV All-Russian Theoretical and Practical Conference "Professional and personal self-determination of youth in modern Russia]. Samara, SamLiuksPrint Publ., 2013, pp. 3-8.

4. Akopov G. V. Metodologicheskie osnovaniia kontsepta «sozertsanie» v sovremennoi psikhologii [Methodological foundations of the "contemplation" concept in modern psychology]. Materialy Vserossiiskoi konferentsii: "Sozertsanie kak sovremennaia nauchno-teoreticheskaia i prikladnaia problema" [Proc. the All-Russian Conference "Contemplation as a modern scientifictheoretical and applied problem]. Samara, Volga Region State Social and Humanitarian Academy Publ., 2013, pp. 10-17.

5. Akopov G. V. Sozertsanie kak predmet psikhologicheskikh issledovanii [Contemplation as a subject of psychological researches]. Materialy Povolzhskogo konsolidiruiushchego seminara "Sozertsanie kak sovremennaia nauchno-teoreticheskaia i prikladnaia problema" [Proc. the Volga Region Consolidating Seminar "Contemplation as a modern scientific-theoretical and applied problem"]. Samara, Volga Region State Social and Humanitarian Academy Publ., 2011, pp. 36-44.

6. Akopian L. S. Predstavleniia o fenomene sozertsaniia u studentov [Perception of a contemplation phenomenon among students]. Materialy vserossiiskoi konferentsii: "Sozertsanie kak sovremennaia nauchno-teoreticheskaia i prikladnaia problema" [Proc. the All-Russian Conference "Contemplation as a modern scientific-theoretical and applied problem"]. Samara, Volga Region State Social and Humanitarian Academy Publ., 2013, pp. 144-147.

7. Asmolov A. G. Po tu storonu soznaniia: metodologicheskie problemy neklassicheskoi psikhologii [Beyond consciousness: methodological problems of nonclassical psychology]. Moscow, Smysl Publ., 2002.

8. Bakshutova E. V. Ob aksiologicheskom kontekste sozertsaniia [On the axiological context of contemplation]. Materialy vserossiiskoi konferentsii: "Sozertsanie kak sovremennaia nauchno-teoreticheskaia i prikladnaia problema" 
[Proc. the All-Russian Conference "Contemplation as a modern scientifictheoretical and applied problem"]. Samara, Volga Region State Social and Humanitarian Academy Publ., 2013, pp. 74-82.

9. Bekhterev V. M. Ob"ektivnaia psikhologiia [Objective psychology]. Moscow, Nauka Publ., 1991.

10. BodrovV. A. Sovremennye predstavleniia o chuvstve ustalosti v professional'noi deiatel'nosti [Modern ideas about the feeling of tiredness in professional activities]. Psikhologicheskii zhurnal - Psychological Journal, 2012, V. 33, no. 2, pp. 23-34.

11. Brushlinskii A. V. Problema bessoznatel'nogo v trudakh S. L. Rubinshteina [The problem of unconscious in S. L. Rubenstein's works]. Voprosy PsychologiiApproaches to Psychology, 1979, no. 3, pp. 115-122.

12. Garber I. E. Sozertsanie i soznanie: sravnitel'nyi kognitivnyi analiz [Contemplation and consciousness: comparative cognitive analysis]. Materialy Povolzhskogo konsolidiruiushchego seminara "Sozertsanie kak sovremennaia nauchno-teoreticheskaia i prikladnaia problema" [Proc. the Volga Region Consolidating Seminar "Contemplation as a modern scientifictheoretical and applied problem"]. Samara, Volga Region State Social and Humanitarian Academy Publ., 2011, pp. 44-49.

13. Golenkov S. I. Kul'tura, smysl, soznanie [Culture, sense, consciousness]. Samara, Samara University Publ., 1996.

14. Grigorian E. G. Sozertsanie ili «vnimatel'noe nabliudenie» [Contemplation or "attentive supervision"]. Materialy Povolzhskogo konsolidiruiushchego seminara "Sozertsanie kak sovremennaia nauchno-teoreticheskaia i prikladnaia problema" [Proc. the Volga Region Consolidating Seminar "Contemplation as a modern scientific-theoretical and applied problem"]. Samara, Volga Region State Social and Humanitarian Academy Publ., 2011, pp. 49-55.

15. Doroshko K. G. Sootnoshenie poniatii "otsepenenie"i "sozertsanie"[Correlation of "entrancement" and "contemplation" concepts]. Materialy vserossiiskoi konferentsii: "Sozertsanie kak sovremennaia nauchno-teoreticheskaia i prikladnaia problema" [Proc. the All-Russian Conference "Contemplation as a modern scientific-theoretical and applied problem"]. Samara, Volga Region State Social and Humanitarian Academy Publ., 2013, pp. 37-40.

16. Dubovyi L. M. Vvedenie v psikhologiiu smysla [Introduction to sense psychology]. Penza, 2006.

17. ZinchenkoV.P.Psikhologicheskie osnovy pedagogiki [Psychological foundations of pedagogics]. Moscow, Gardariki Publ., 2002.

18. Znakov V. V. Samosoznanie, samoponimanie i ponimaiushchee sebia bytie [Self-consciousness, self-understanding and the existence understanding 
itself]. Metodologiia $\mathrm{i}$ istoriia psikhologii - Methodology and History of Psychology, 2007, V. 2, no. 3, pp. 65-74.

19. Il'in E. P. Emotsii i chuvstva [Emotions and feelings]. St. Petersburg, Piter Publ., 2001.

20. Karitskii I. N. Psikhologicheskie praktiki vnutrennego sozertsaniia real'nosti [Psychological practices of internal contemplation of reality]. Materialy Povolzhskogo konsolidiruiushchego seminara "Sozertsanie kak sovremennaia nauchno-teoreticheskaia i prikladnaia problema" [Proc. the Volga Region Consolidating Seminar "Contemplation as a modern scientific-theoretical and applied problem"]. Samara, Volga Region State Social and Humanitarian Academy Publ., 2011, pp. 112-127.

21. Krasil'nikov I. A. Sozertsatel'nost' kak spontanno-smyslovoi kontrol' sub"ekta pri razreshenii vnutrilichnostnykh konfliktov [Meditativeness as a spontaneous-sense control of the subject in resolving intrapersonal conflicts]. Materialy Povolzhskogo konsolidiruiushchego seminara "Sozertsanie kak sovremennaia nauchno-teoreticheskaia i prikladnaia problema" [Proc. the Volga Region Consolidating Seminar"Contemplation as a modern scientifictheoretical and applied problem"]. Samara, Volga Region State Social and Humanitarian Academy Publ., 2011, pp. 192-197.

22. Leont'ev D. A. Psikhologiia smysla: priroda, stroenie i dinamika smyslovoi real'nosti [The psychology of sense: nature, structure and dynamics of the sense reality]. Moscow, Smysl Publ., 1999.

23. Mamardashvili M. K. Kartezianskie razmyshleniia [Cartesian reflections]. Moscow, Progress, Culture Publ., 1993.

24. Melik-Pashaev A. A. O sozertsatel'noi osnove khudozhestvennogo tvorchestva [On the contemplative basis of artistic creativity]. Materialy Povolzhskogo konsolidiruiushchego seminara "Sozertsanie kak sovremennaia nauchnoteoreticheskaia i prikladnaia problema" [Proc. the Volga Region Consolidating Seminar "Contemplation as a modern scientific-theoretical and applied problem"]. Samara, Volga Region State Social and Humanitarian Academy Publ., 2011, pp. 202-208.

25. Molchanov V. I. Issledovaniia po fenomenologii soznaniia [Researches in the phenomenology of consciousness]. Moscow, Territoriia budushchego Publ., 2007.

26. Mukhrygina O. I. Sozertsatel'nyi aspekt samoreguliatsii sostoianii cheloveka [A contemplative aspect of self-regulation of the person's states]. Materialy Povolzhskogo konsolidiruiushchego seminara "Sozertsanie kak sovremennaia nauchno-teoreticheskaia i prikladnaia problema" [Proc. the Volga Region Consolidating Seminar "Contemplation as a modern scientific-theoretical and applied problem"]. Samara, 
Volga Region State Social and Humanitarian Academy Publ., 2011, pp. 208-211.

27. Nizovskikh N. A., Nikolaev S. G., Vtiurina T. A. Mental'nye reprezentatsii sozertsaniia [Mental representations of contemplation]. Materialy vserossiiskoi konferentsii: "Sozertsanie kak sovremennaia nauchno-teoreticheskaia i prikladnaia problema" [Proc. the All-Russian Conference "Contemplation as a modern scientific-theoretical and applied problem"]. Samara, Volga Region State Social and Humanitarian Academy Publ., 2013, pp. 147-155.

28. Panov V. I. Vvedenie v ekologicheskuiu psikhologiiu [Introduction to ecological psychology]. Moscow, Shkol'nye tekhnologii Publ., 2006.

29. Pergamenshchik L. A. Psikhicheskoe otsepenenie kak razryv nepreryvnosti bytiia [Mental entrancement as a rupture of the continuity of being]. Zhurnal prakticheskogo psikhologa - Journal of a Practical Psychologist, 2009, no. 1, pp. 156-165.

30. Petrenko V. F. Dukhovno-psikhologicheskoe i estestvennonauchnoe obosnovanie sozertsaniia [Spiritual-psychological and natural-science grounds of contemplation]. Materialy vserossiiskoi konferentsii: "Sozertsanie kak sovremennaia nauchno-teoreticheskaia i prikladnaia problema" [Proc. the All-Russian Conference "Contemplation as a modern scientific-theoretical and applied problem"]. Samara, Volga Region State Social and Humanitarian Academy Publ., 2013, pp. 6-10.

31. Petrenko V. F., Kucherenko V.V. Meditatsiia kak neoposredovannoe poznanie [Meditation as a unmediated knowledge]. Metodologiia i istoriia psikhologiiMethodology and History of Psychology, 2007, V. 2, no. 1, pp. 164-190.

32. Pomerants G. S. The pause of contemplation. Available at: http://magazines. russ.ru/druzhba/2002/2/pom.html

33. Prokhorov A. O., Bekhtereva V.D. Izmenennye sostoianiia soznaniia. Psikhologiia sostoianii [Altered states of consciousness. The psychology of states]. Moscow, Kogito-Tsentr Publ., 2011, pp. 277-306.

34. Rubinshtein S. L. Bytie i soznanie. Chelovek i mir [Being and consciousness. A man and the world]. St. Petersburg, 2003.

35. Rulina T. K. Zapadnoevropeiskaia traditsiia umnogo zreniia [West European tradition of a smart view]. Materialy vserossiiskoi konferentsii: "Sozertsanie kak sovremennaia nauchno-teoreticheskaia i prikladnaia problema" [Proc. the All-Russian Conference "Contemplation as a modern scientific-theoretical and applied problem"]. Samara, Volga Region State Social and Humanitarian Academy Publ., 2013, pp. 66-74.

36. Semenova T. V. O problemakh diagnostiki sozertsaniia [On problems of the diagnostics of contemplation]. Materialy vserossiiskoi konferentsii: "Sozertsanie kak sovremennaia nauchno-teoreticheskaia i prikladnaia problema" [Proc. the 
All-Russian Conference "Contemplation as a modern scientific-theoretical and applied problem"]. Samara, Volga Region State Social and Humanitarian Academy Publ., 2013, pp. 155-159.

37. Shestun G., Podorovskaia I. A. Sviatootecheskoe ponimanie sozertsaniia [The patristic understanding of contemplation]. Materialy Povolzhskogo konsolidiruiushchego seminara "Sozertsanie kak sovremennaia nauchnoteoreticheskaia i prikladnaia problema" [Proc. the Volga Region Consolidating Seminar "Contemplation as a modern scientific-theoretical and applied problem"]. Samara, Volga Region State Social and Humanitarian Academy Publ., 2011. 